LIMA, Luciana Cristina da Conceição; REI, Fernando Cardozo Fernandes. O papel da Soft Law privada no enfrentamento da problemática socioambiental global. Revista Eletrônica Direito e Política, Programa de Pós-Graduação Stricto Sensu em Ciência Jurídica da UNIVALI, Itajaí, v.13, n.2, 20 quadrimestre de 2018. Disponível em: www.univali.br/direitoepolitica - ISSN 1980-7791

\title{
O PAPEL DA SOFT LAW PRIVADA NO ENFRENTAMENTO DA PROBLEMÁTICA SOCIOAMBIENTAL GLOBAL
}

\author{
THE ROLE OF SOFT LAW PRIVATE IN THE FACING OF GLOBAL SOCIO- \\ ENVIRONMENTAL PROBLEM
}

\section{Luciana Cristina da Conceição Lima1 \\ Fernando Cardozo Fernandes $\mathbf{R e i}^{2}$}

\begin{abstract}
SUMÁRIO: Introdução; 1 Soft Law pública e privada: definições, alcances e limites no processo da governança global; 2 Ascensão de normas privadas na regulamentação da responsabilidade socioambiental empresarial; 3 Normas socioambientais privadas: mecanismos não estatais de solução de controvérsias globais; Considerações Finais; Referência das fontes citadas.
\end{abstract}

\section{RESUMO}

A incapacidade dos Estados em gerir e equacionar as complexas questões socioambientais globais gerou uma oportunidade de regulamentação jurídica, representada pela normatização internacional de atividades empresariais diretamente relacionada com tais questões. O presente artigo objetiva analisar a crescente ascensão das normas privadas no contexto da governança global, relacionando aspectos importantes dessa espécie normativa com o alcance e limites de instrumentos não vinculantes no enfrentamento de conflitos e problemas socioambientais globais. O estudo buscou relacionar a lacuna jurídica identificada com a nova ordem global de interesse e participação de novos atores em assuntos públicos, demonstrando a diferença entre soft law pública e privada. Contextualizaram-se algumas das iniciativas privadas de adoção voluntária, que tratam de práticas relacionadas à responsabilidade social, ao meio ambiente e à sustentabilidade, para analisar, em que medida, iniciativas normativas como essas podem instituir um campo de regulamentação que seja capaz de criar um contexto de regras e normas respeitadas pela comunidade global.

Palavras-chave: Normas Socioambientais Privadas; Governança Global; Instrumentos juridicamente não vinculantes; Solução de Conflitos.

1 Doutoranda em Direito Ambiental Internacional pela Universidade Católica de Santos (UNISANTOS), Santos-SP, Brazil. Mestre em Sistemas de Gestão pela Universidade Federal Fluminense (UFF), Niterói-RJ, Brasil. MBA em Organizações e Estratégia pela Universidade Federal Fluminense (UFF), Niterói-RJ, Brasil. Bacharel em Direito pela Universidade Católica de Santos (UNISANTOS), Santos-SP, Brazil. Bacharel em Pedagogia pela Universidade Federal de Minas Gerais (UFMG), Belo Horizonte-MG, Brasil. E-mail: Iulima@icloud.com

2 Ambiental Internacional da Universidade Católica de Santos. Professor Titular de Direito Ambiental da Fundação Armando Álvares Penteado (FAAP). Diretor Científico da Sociedade Brasileira de Direito Internacional do Meio Ambiente (SBDIMA). É Doutor em Direito Internacional pela Universidade de São Paulo e Doutor em Direito do Estado/Direito Ambiental - Universidad de Alicante. E-mail: fernandorei@ig.com.br 
LIMA, Luciana Cristina da Conceição; REI, Fernando Cardozo Fernandes. O papel da Soft Law privada no enfrentamento da problemática socioambiental global. Revista Eletrônica Direito e Política, Programa de Pós-Graduação Stricto Sensu em Ciência Jurídica da UNIVALI, Itajaí, v.13, n.2, 20 quadrimestre de 2018. Disponível em: www.univali.br/direitoepolitica - ISSN 1980-7791

\begin{abstract}
The inability of the states to manage and address the complex global socioenvironmental issues generated an opportunity for legal regulation, represented by the international standardization of business activities directly related to such issues. The present article aims to analyze the increasing rise of private norms in the context of global governance, relating important aspects of this normative species with the scope and limits of non - binding instruments in the confrontation of conflicts and global socio-environmental problems. The study sought to relate the legal gap identified with the new global order of interest and participation of new actors in public affairs, demonstrating the difference between public and private soft law. Some of the private initiatives for voluntary adoption, dealing with practices related to social responsibility, the environment and sustainability have been contextualized in order to analyze, to what extent, regulatory initiatives such as these can establish a field of regulation capable of creating a context of rules and norms respected by the global community.
\end{abstract}

Keywords: Private Socioenvironmental Standards; Global Governance; Nonlegally binding instruments; Conflict Resolution.

\title{
INTRODUÇÃo
}

Os problemas socioambientais globais exigem respostas urgentes, por meio do desenvolvimento de mecanismos eficientes para seu enfrentamento. No Direito Internacional Público ainda há certa hegemonia na atuação dos Estados e Organizações Internacionais no processo de tomada de decisões para a solução de diversos problemas globais.

Com o advento da globalização ${ }^{3}$ e seus efeitos, abre-se um cenário de mudanças profundas que trazem um novo "paradigma pautado na 'redistribuição' do poder

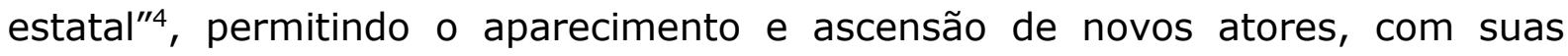
influências, conhecimentos e pressões que levam ao surgimento de uma "sociedade global"5 pluridimensional e, consequentemente, de uma nova sistemática de tomada de decisões no cenário internacional. Nesse contexto,

\footnotetext{
${ }^{3}$ A Globalização é definida como "a intensificação das relações sociais em escala mundial, que ligam localidades distantes de tal maneira que acontecimentos locais são modelados por eventos ocorrendo a muitas milhas de distância e vice-versa". GIDDENS, Anthony. As consequências da modernidade. Unesp, 1990, p.59.
}

${ }^{4}$ MATIAS, Eduardo Felipe P. A humanidade e suas fronteiras: do Estado soberano à sociedade global. 4a ed. São Paulo: Paz e Terra, 2014, p. 445.

${ }^{5}$ MATIAS, Eduardo Felipe P. A humanidade e suas fronteiras: do Estado soberano à sociedade global, p. 123. 
LIMA, Luciana Cristina da Conceição; REI, Fernando Cardozo Fernandes. O papel da Soft Law privada no enfrentamento da problemática socioambiental global. Revista Eletrônica Direito e Política, Programa de Pós-Graduação Stricto Sensu em Ciência Jurídica da UNIVALI, Itajaí, v.13, n.2, $2^{\circ}$ quadrimestre de 2018. Disponível em: www.univali.br/direitoepolitica - ISSN 1980-7791

verifica-se que os Estados não só estão em condição de maior dependência uns dos outros, bem como de novos grupos de poder e pressão, diante de um contexto de crescentes problemas de ordem econômica, ambiental e social que requer o desenvolvimento de atividades e mecanismos de cooperação e regulação internacional. Esta necessidade de cooperação na ordem internacional resultou na organização e ascensão de outras instituições no campo internacional e no uso crescente de instrumentos jurídicos não obrigatórios, conhecidos como soft law ${ }^{6}$. Trata-se na verdade de um processo de transformação do direito internacional através de normas não vinculantes, implicando, no fundo, numa revolução no campo das fontes desse direito ${ }^{7}$.

E essa discussão em torno do valor jurídico da soft law é antiga ${ }^{8}$.

Atribuir uma definição para soft law tem sido uma tarefa intricada entre os doutrinadores $^{9}$, porque a própria expressão soft law pode ensejar um paradoxo. Tal paradoxo advém da simples ideia de que direito representa em geral algo obrigatório, capaz de impor sanção, ou seja, um conceito oposto a algo não obrigatório, genérico, flexível. Logo, pergunta-se se o adjetivo soft utilizado para qualificar o direito suscita de início que esta nova norma se difere do direito em sua acepção usual constituindo-se assim num direito diferenciado ou, ainda, se o uso do termo soft indica tratar-se de algo que não seja necessariamente direito.

Para Shelton (2009), soft law "é um tipo de norma social e não legal" que, geralmente, "refere-se a qualquer instrumento internacional por escrito, à exceção de um tratado, contendo princípios, normas, padrões, ou outras declarações sobre

\footnotetext{
${ }^{6}$ FRIEDRICH, Jürgen. International Environmental "soft law": The Functions and Limits of Nonbinding Instruments in International Environmental Governance and Law. Springer Science \& Business Media, 2013, p.19.
}

${ }^{7}$ NASSER, Salem Hikmat. Desenvolvimento, costume internacional e soft law. Direito Internacional e Desenvolvimento, v. 1, p. 201-218, 2005, p. 216.

${ }^{8}$ VIRALLY, Michel. La valeur juridique des recommandations des organisations internationales. Annuaire français de droit international, v. 2, n. 1, p. 66-96, 1956.

${ }^{9}$ SALMON, Jean. Dictionnaire de droit international public. Bruxelas : Bruylant, 2001. p. 1039. 
LIMA, Luciana Cristina da Conceição; REI, Fernando Cardozo Fernandes. O papel da Soft Law privada no enfrentamento da problemática socioambiental global. Revista Eletrônica Direito e Política, Programa de Pós-Graduação Stricto Sensu em Ciência Jurídica da UNIVALI, Itajaí, v.13, n.2, 20 quadrimestre de 2018. Disponível em: www.univali.br/direitoepolitica - ISSN 1980-7791

o comportamento esperado"10. Para Nasser (2005), algum direito, diz-se, resulta desses instrumentos. Seria, ao menos, um direito em gestação ${ }^{11}$. O consenso parece estar na sua capacidade de regular os comportamentos por meio de normas e regras que não são juridicamente obrigatórias, mas que representam certa pressão de comportamento e resultado, já que dispõe sobre as condutas dos atores sociais e até mesmo expectativas em relação a essas condutas. De qualquer forma, parece haver consenso que se diferencia a soft law de outras normas pelo seu caráter de flexibilidade e dependência do processo de governança.

Verifica-se, então, com a consolidação do processo de governança global, a ascensão de atores privados no cenário internacional que contribuem para a aceleração desse processo. As empresas transnacionais atuam nesse contexto globalizado de produção, mercados e investimentos que acabam influenciando o poder dos estados e suas relações internacionais ${ }^{12}$.

A construção de uma regulamentação privada, através da elaboração de instrumentos para tratar das questões socioambientais globais, apoia-se em uma governança global estruturada na participação ampliada e na cooperação para o estabelecimento de consensos com a finalidade de solucionar problemas comuns. Desse processo, surge a "globalização jurídica"13, trazendo a possibilidade de governanças normativas paralelas à ordem jurídica estatal. Essa espécie de governança adquire eficácia a partir da legitimidade decorrente da participação dos atores, envolvidos na formulação de suas regras e da sua utilização, condição

\footnotetext{
${ }^{10}$ SHELTON, Dinah. Soft law. Routledge handbook of international law, Routledge Press; GWU Legal Studies Research Paper No. 322; GWU Law School Public Law Research Paper No. 322, 2009. Disponível em: <http://ssrn.com/abstract=1003387>. Acesso em 21 jan. 2017.
}

${ }^{11}$ NASSER, Salem Hikmat. Desenvolvimento, costume internacional e soft law. Direito Internacional e Desenvolvimento, v. 1, p. 201-218, 2005, p. 216.

12MATIAS, Eduardo Felipe P. A humanidade e suas fronteiras: do Estado soberano à sociedade global, p. 123.

${ }^{13} \mathrm{~A}$ globalização jurídica pode ser definida como o "aumento do número de regras internacionais" públicas ou privadas que buscam regulamentar assuntos internacionais de interesse comum (MATIAS, Eduardo Felipe P. A humanidade e suas fronteiras: do Estado soberano à sociedade global, p. 227). 
LIMA, Luciana Cristina da Conceição; REI, Fernando Cardozo Fernandes. O papel da Soft Law privada no enfrentamento da problemática socioambiental global. Revista Eletrônica Direito e Política, Programa de Pós-Graduação Stricto Sensu em Ciência Jurídica da UNIVALI, Itajaí, v.13, n.2, 20 quadrimestre de 2018. Disponível em: www.univali.br/direitoepolitica - ISSN 1980-7791

que as podem tornar tão eficazes quanto normas produzidas pelos Estados em acordos e tratados multilaterais.

O presente artigo analisa, sob a perspectiva da dinâmica da governança global ${ }^{14}$, a ascensão de instrumentos normativos voluntários e privados, que buscam contribuir para a solução dos complexos problemas socioambientais. Esse fenômeno ocorre porque as empresas acabam criando e adotando políticas, regras, normas e padrões, que são desenvolvidos para a criação de um universo normativo paralelo ao Estatal, com a finalidade de efetivar o controle da conformidade no enfrentamento dos problemas e conflitos globais que Ihes afetam. Nesse sentido, buscou-se compreender como são construídos esses instrumentos normativos não vinculantes e privados, bem como a razão pela qual as empresas têm desenvolvido essas normas, que atuam simultânea ou conjuntamente com normas estatais no tratamento de questões socioambientais.

Diante disso, este estudo buscou contextualizar a temática com algumas normas privadas que cuidam de questões socioambientais em âmbito global, para compreender o avanço do processo de regulamentação normativa privado, que é capaz de criar um universo paralelo de regras, não especificamente oriundas do poder soberano dos Estados, mas que criam um contexto de normas e diretrizes aceitas e incorporadas pela comunidade global.

\footnotetext{
${ }^{14}$ Governança Global é um temo trazido do conceito de governança que pressupõe a inter-relação de diversos atores (governos, Organizações Internacionais, empresa e representantes da sociedade civil), criando estratégias e mecanismos para a solução de problemas comuns, mas em âmbito global. A Governança Global é um meio, mecanismo ou processo eficaz de solução de problemas, que podem ser dos mais variados. Trata-se de um processo que será construído por cada necessidade ou situação (GONÇALVES, Alcindo. Governança Global. In: GONÇALVES, Alcindo e COSTA, José Augusto Fontoura. Governança Global e Regimes Internacionais. São Paulo: Almedina, 2011, p.83).
} 
LIMA, Luciana Cristina da Conceição; REI, Fernando Cardozo Fernandes. O papel da Soft Law privada no enfrentamento da problemática socioambiental global. Revista Eletrônica Direito e Política, Programa de Pós-Graduação Stricto Sensu em Ciência Jurídica da UNIVALI, Itajaí, v.13, n.2, $2^{\circ}$ quadrimestre de 2018. Disponível em: www.univali.br/direitoepolitica - ISSN 1980-7791

\section{SOFT LAW PÚBLICA E PRIVADA: DEFINIÇÕES, ALCANCES E LIMITES NO PROCESSO DA GOVERNANÇA GLOBAL}

O termo soft law é normalmente associado a normas não vinculantes. O que o diferencia de hard law é a natureza do seu efeito vinculativo: a hard law é juridicamente vinculante, trazendo consequências legais sobre 0 não adimplemento e a não conformidade. Por outro lado, a soft law, não sendo vinculante, adquire força pela materialidade do que pretende regular como regra internacional voluntária e definida por consensos ${ }^{15}$. A flexibilidade é outra característica das normas não vinculantes. São normas que se propõem a uma determinada finalidade, permitindo adequações e ajustes para atingir seus objetivos, proporcionando, portanto, o alcance de resultados mais adequados e eficazes e que acompanhem a evolução das questões, nomeadamente no aspecto técnico e científico, nesse novo contexto global tão dinâmico ${ }^{16}$.

As normas não vinculantes, muitas vezes, proporcionam formas mais eficientes e eficazes de solução de problemas, pois sua formulação, frequentemente, conta com a cooperação de atores diversos, que apesar de defenderem diferentes interesses, constroem um consenso a partir de objetivos comuns. O termo "soft" relacionado à norma, não deve ser confundido com fraco ou menos eficaz. Pelo contrário, deve ser entendido como um adjetivo que define sua maior flexibilidade e capacidade de ser modificada ou adaptada às necessidades do seu público de interesse ${ }^{17}$.

É certo que o enfrentamento dos complexos problemas socioambientais encontra campo fértil no fenômeno da soft law. Essa espécie normativa pode ser encontrada nos encaminhamentos propostos pelas resoluções da Assembleia Geral, pelas Declarações de Estocolmo e do Rio de Janeiro, pela Agenda 21 e Objetivos do

${ }^{15}$ BEYERLIN, Ulrich; MARAUHN, Thilo. International Environmental Law. Oxford: Hart Publishing, 2011, p. 290.

\footnotetext{
${ }^{16}$ FRIEDRICH, Jürgen. International Environmental soft law: The Functions and Limits of Nonbinding Instruments, p.29.

${ }^{17} A B B O T T$, Kenneth W.; SNIDAL, Duncan. Hard and soft law in international governance. International organization, v. 54, n. 03, p. 421-456, 2000.
} 
LIMA, Luciana Cristina da Conceição; REI, Fernando Cardozo Fernandes. O papel da Soft Law privada no enfrentamento da problemática socioambiental global. Revista Eletrônica Direito e Política, Programa de Pós-Graduação Stricto Sensu em Ciência Jurídica da UNIVALI, Itajaí, v.13, n.2, $2^{\circ}$ quadrimestre de 2018. Disponível em: www.univali.br/direitoepolitica - ISSN 1980-7791

Desenvolvimento Sustentável, bem como, pela crescente produção de normas internacionais de iniciativa privada, como no caso das normas técnicas socioambientais da ISO.

As normas não vinculantes podem ser de origem pública ou privada ${ }^{18}$. A principal diferença entre soft law pública e privada é a fonte da sua autoridade. Ou seja, são consideradas como públicas quando emanam da autoridade Estatal ou de Organizações Internacionais. São da mesma forma normas não vinculantes e não possuem, a rigor, sanções pelo seu descumprimento. Por outro lado, a soft law privada não se origina exclusivamente do poder Estatal. "Muitas vezes, os atores privados são os principais responsáveis pela criação dessas regras, que surgem, independentemente da vontade dos Estados"19. Sua formulação decorre de processos privados, que podem, ou não, contar com a participação de governos e de Organizações Internacionais em um contexto de governança que conte com participação ampliada e cooperação no enfrentamento das questões de interesses comuns. É um contexto em que outros atores atuam "operando ao lado ou ao redor do Estado, e não através dele"20.

São normas que possuem estruturas e procedimentos regulatórios privados e seu controle está concentrado na esfera privada. No entanto, também compartilham das mesmas características, ou seja, são de adoção voluntária, não possuem sanção pelo descumprimento e, a princípio, não vinculam seus destinatários. A característica principal das normas privadas reside no seu pragmatismo e finalidade. São normas que decorrem de uma demanda global para alcançar e resolver determinado tema, definindo sempre seu público alvo e de interesse. Criam-se procedimentos, condutas e práticas que buscam não conflitar ou superar

\footnotetext{
18 VOGEL, David. The private regulation of global corporate conduct. Center for Responsible Business, 2006, p.04.

19MATIAS, Eduardo Felipe P. A humanidade e suas fronteiras: do Estado soberano à sociedade global, 2015, p. 227.

${ }^{20}$ VOGEL, David. The private regulation of global corporate conduct. Center for Responsible Business, 2006, p.04.
} 
LIMA, Luciana Cristina da Conceição; REI, Fernando Cardozo Fernandes. O papel da Soft Law privada no enfrentamento da problemática socioambiental global. Revista Eletrônica Direito e Política, Programa de Pós-Graduação Stricto Sensu em Ciência Jurídica da UNIVALI, Itajaí, v.13, n.2, $2^{\circ}$ quadrimestre de 2018. Disponível em: www.univali.br/direitoepolitica - ISSN 1980-7791

normas legais ou acordos globais já estabelecidos ${ }^{21}$. Pelo contrário, em muitos casos, esses acordos servem como base ou referência para a construção dessas normas. No entanto, a finalidade das normas privadas é criar formas de implementação de práticas que permitam o alcance concreto e eficaz de objetivos globais, perseguidos em determinadas temáticas.

$\mathrm{Na}$ elaboração de normas privadas, pode haver a participação dos Estados/governos, que, neste caso, atuam como partes interessadas, parceiros e colaboradores do processo de governança estabelecido. Assim, a autoridade do processo é compartilhada e horizontal. Sua aplicação geralmente é ampla, abrangendo diversos ou quaisquer tipos de organizações, incluindo organizações públicas. As normas socioambientais privadas costumam se basear em acordos internacionais multilaterais, em normas não vinculantes produzidas pelos Estados e suas Organizações internacionais e, também, em normas legais vinculantes criadas pelos Estados com o intuito de regulamentar determinadas atividades e processos como a proteção ambiental e dos direitos humanos. As normas privadas não possuem finalidade de substituir normas internacionais ou internas ${ }^{22}$ dos Estados, mas são capazes de ampliar o seu alcance e de criar procedimentos, mecanismos e ferramentas eficazes de implementação de regras e condutas que buscam solucionar problemas e conflitos globais.

Os limites da atuação empresarial nas questões socioambientais podem esbarrar na necessidade e relevância da temática para as empresas. A aplicação das normas e regras socioambientais esbarra, portanto, na satisfação dos seus interesses e de seus stakeholders ${ }^{23}$. A implementação de novas regras e práticas "mais

\footnotetext{
${ }^{21}$ VOGEL, David. The private regulation of global corporate conduct. Center for Responsible Business, 2006, p.06.

22 No caso de Cuba, não obstante se reconheça o caráter voluntário da norma, por interesses do Estado, é possível que seja convertida em obrigatória, segundo o que dispõe o Decreto-Lei 182 de Normatização e Qualidade e suas disposições complementares. Fonte: ESTRATEGIA PARA LA IMPLEMENTACIÓN DE LAS NORMAS NC-ISO 14000. Disponível em http://archives.valoryempresa.com/archives3/estrategia14000.pdf.pdf. Acesso em 01 jun. 2017.
}

${ }^{23}$ Steakholder é definido por Freeman, 2004 como: "qualquer grupo ou indivíduo, que afeta ou é afetado pela realização do objeto de uma organização". FREEMAN, R. Edward. The stakeholder approach revisited. Zeitschrift für Wirtschafts-und Unternehmensethik, v. 5, n. 3, p. 228, 2004. Disponível em:

http://citeseerx.ist.psu.edu/viewdoc/download?doi=10.1.1.466.6445\&rep=rep1\&type=pdf $>$. 
LIMA, Luciana Cristina da Conceição; REI, Fernando Cardozo Fernandes. O papel da Soft Law privada no enfrentamento da problemática socioambiental global. Revista Eletrônica Direito e Política, Programa de Pós-Graduação Stricto Sensu em Ciência Jurídica da UNIVALI, Itajaí, v.13, n.2, $2^{\circ}$ quadrimestre de 2018. Disponível em: www.univali.br/direitoepolitica - ISSN 1980-7791

responsáveis" pode gerar aumento de custos, pela própria proliferação de procedimentos, que elevem os preços de produtos ou serviços.

Esta é inclusive uma desvantagem identificada por alguns doutrinadores ${ }^{24}$, decorrentes do incremento de procedimentos derivados da soft law, que poderia ameaçar a dinâmica da lógica jurídica institucional. É como se fosse um ciclo vicioso: as empresas se vêm pressionadas a adotar comportamentos mais éticos, responsáveis e sustentáveis, que demandam investimentos com a implementação de novas técnicas e regras. Por outro lado, pode não estar disposta ou não considerar a elevação de custos no atendimento a alguns requisitos, situação que pode dificultar a decisão da organização em adotar medidas ou normas que atendam a certa demanda, mas que possam conflitar com outros interesses.

Dessa forma, os limites estão em compreender até que ponto uma organização pode, precisa e deve atuar nas questões socioambientais, de forma a atender e participar das soluções de problemas globais, mas sem afetar seus negócios e lucratividade. Afinal, se por um lado há demanda pela responsabilidade organizacional, por outro, existe demanda por qualidade, eficiência com menor custo, critérios que podem ser afetados pela adoção de práticas ou outros procedimentos, em tese considerados diversos ou alheios ao negócio.

$\mathrm{Na}$ verdade, as empresas já detêm um conhecimento de processo inovadores de gestão que respondem a essas demandas socioambientais. Exemplos não faltam. Contudo, com o aumento de novas regras e normas, em particular coma implementação das metas dos ODS, reclama-se uma maior parceria dos setores empresariais com as instituições governamentais e sociais, onde, inclusive, esse know how empresarial pode ser extremamente valioso e determinante para dar escala às boas práticas.

Acesso em 10 fev. 2017.

24 EISEMANN, Pierre Michel. The gentleman's agreement comme source du droit international. Jounal du Droit International. 1979, p. 326-348. 
LIMA, Luciana Cristina da Conceição; REI, Fernando Cardozo Fernandes. O papel da Soft Law privada no enfrentamento da problemática socioambiental global. Revista Eletrônica Direito e Política, Programa de Pós-Graduação Stricto Sensu em Ciência Jurídica da UNIVALI, Itajaí, v.13, n.2, $2^{\circ}$ quadrimestre de 2018. Disponível em: www.univali.br/direitoepolitica - ISSN 1980-7791

\section{ASCENSÃo de NORMAS PRIVAdAS NA REgULAMENTAÇÃo DA RESPONSABILIDADE SOCIOAMBIENTAL EMPRESARIAL}

O processo de globalização, com a consequente abertura das fronteiras modificou o cenário internacional, tanto para o comércio e relações entre Estados, quanto para as questões sociais, culturais e ambientais. Esse novo cenário alterou, ainda, a forma como os problemas são tratados ou solucionados no âmbito internacional, fomentando as relações multilaterais baseadas no diálogo, persuasão, enfrentamento conjunto e, principalmente, na cooperação. A globalização facilitou a transnacionalização das empresas, que tiveram seu espaço e alcance ampliados, o que permitiu o estabelecimento de companhias em diferentes países ou regiões do mundo. As transnacionais emergiram com grande força e se espalharam rapidamente, conseguindo criar nichos de atividades econômicas capazes de superar economias nacionais, considerando, inclusive, suas transações internacionais ${ }^{25}$.

A atuação global das empresas transnacionais proporcionou a redução de custos com contratação de mão de obra, melhor controle da cadeia produtiva e de suprimentos, além da possibilidade de análise e escolha sobre a legislação e regras mais convenientes para atuação em determinado mercado ou setor. Por outro lado, esse processo de transnacionalização trouxe efeitos não desejados em diversos outros aspectos como degradação ambiental, violação de direitos humanos, questões referentes às relações de trabalho e sua exploração e aumento da desigualdade social. São problemas que antes eram vistos como restritos aos territórios nacionais, mas que passaram a uma escala global e de difícil controle estatal.

A preocupação com os impactos sociais e ambientais decorrentes da globalização e da atuação das empresas no cenário internacional traz novas demandas globais $^{26}$. A liberdade de atuação mundial, transferida às empresas transnacionais,

\footnotetext{
${ }^{25}$ RUGGIE, John Gerard. Quando os negócios não são apenas negócios: as corporações multinacionais e os direitos humanos. Trad. Isabel Murray - $1^{a}$ ed. - São Paulo: Editora Abril, 2014, p. 17.
}

26ZERK, Jennifer A. Multinationals and corporate social responsibility: Limitations and 
LIMA, Luciana Cristina da Conceição; REI, Fernando Cardozo Fernandes. O papel da Soft Law privada no enfrentamento da problemática socioambiental global. Revista Eletrônica Direito e Política, Programa de Pós-Graduação Stricto Sensu em Ciência Jurídica da UNIVALI, Itajaí, v.13, n.2, $2^{\circ}$ quadrimestre de 2018. Disponível em: www.univali.br/direitoepolitica - ISSN 1980-7791

pode ser considerada como um grande fator para a crise de poder dos Estados, que mantiveram sua soberania, mas tiveram a redução do controle do mercado e de grandes empresas e corporações. Nessa perspectiva, os governos nacionais, que antes administravam, orientavam e controlavam a movimentação do capital das organizações empresariais, depararam-se com a redução ou redistribuição desse poder, ocorrendo, então, a crise do Estado-nação com a consequente redefinição do seu papel ${ }^{27}$.

Associada a tudo isso está a questão econômica, refletida muitas vezes na necessidade dos países em manter determinadas empresas em seus territórios. Apesar de o Estado ter o direito e autonomia para regular as empresas transacionais que atuam no seu território, eles podem não ter condições de criar normas e regras ou, até mesmo optar por não as criar em função de interesses econômicos ou políticos. Essa situação acaba gerando diferenças e discrepâncias nas regulamentações sociais e ambientais que são exploradas por algumas multinacionais para obterem vantagens comerciais ${ }^{28}$. Por outro lado, o endurecimento de regras e de leis pode acarretar a mudança das empresas para territórios mais atraentes e vantajosos para o negócio. A questão econômica pode ser, nesse aspecto, um grande fator de influência nas relações entre empresas e governos, que acaba por refletir na redução do poder estatal em solucionar os problemas e conflitos socioambientais atuais.

Outra questão importante reside na dificuldade de se estabelecer leis e regras comuns para todas as empresas, pois essas organizações "funcionam como entidades integradas globalmente, mas não estão sujeitas a um regulador único

opportunities in international law. Cambridge University Press, 2006, p.23.

27 IANNI, Octavio. Globalização: novo paradigma das ciências sociais. Estud. av., São Paulo, v. 8, n. 21, p. 147-163, ago. $1994 . \quad$ Disponível em: <http://www.scielo.br/scielo.php?script=sci_arttext\&pid=S010340141994000200009\&lng=en\&nrm=iso > $\quad$ Acesso
2017. http://dx.doi.org/10.1590/S0103-40141994000200009 em: $\quad 12$ fev. opportunities in international law. Cambridge University Press, 2006, p. 23 
LIMA, Luciana Cristina da Conceição; REI, Fernando Cardozo Fernandes. O papel da Soft Law privada no enfrentamento da problemática socioambiental global. Revista Eletrônica Direito e Política, Programa de Pós-Graduação Stricto Sensu em Ciência Jurídica da UNIVALI, Itajaí, v.13, n.2, $2^{\circ}$ quadrimestre de 2018. Disponível em: www.univali.br/direitoepolitica - ISSN 1980-7791

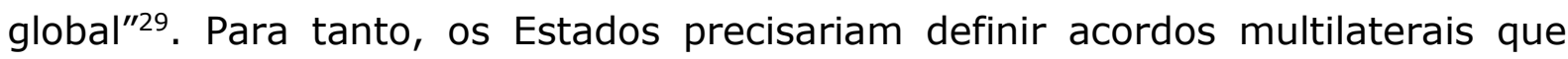
tratassem dessas questões e criar formas de controlar a atuação das empresas transnacionais globalmente. Essa é uma tarefa difícil de se alcançar, principalmente, pela dificuldade atual e crescente de se criar novos acordos multilaterais. Esses acordos exigem consenso na aprovação das deliberações, o que tem sido cada vez mais difícil de atingir. Quando há o consenso, este é frágil, trazendo textos genéricos e sem o apoio de todos os Estados ${ }^{30}$.

Diante disso, por que então o setor privado não se une na construção de práticas globais para tratar de questões geradas pelos efeitos e impactos de sua atuação? $\mathrm{Na}$ medida em que essas regras voluntárias formam um novo marco regulatório para o desenvolvimento das nossas sociedades, elas permitirão que as empresas demonstrem como os seus negócios ajudam no avanço da responsabilidade socioambiental, tanto minimizando os impactos negativos quanto maximizando os impactos positivos nas pessoas e no planeta?

Em princípio a resposta é afirmativa. Cobrindo uma ampla gama dos tópicos de responsabilidade socioambiental relevantes para as empresas, a soft law pode ajudar na conexão de estratégias comerciais com prioridades globais. As empresas podem utilizar as normas privadas como uma referência global para moldar, conduzir, comunicar e relatar as suas estratégias, objetivos e atividades.

Outra resposta para essa questão pode ser encontrada em outro contexto, que também se construiu em decorrências dos efeitos da globalização, qual seja, a ascensão e participação de outros atores não estatais no cenário internacional. A emergência da sociedade civil global ${ }^{31}$, nesse sentido representada pelas ONGs (Organizações Não Governamentais), redesenha uma nova dinâmica das relações internacionais, que necessitam considerar a participação desses atores nos

\footnotetext{
${ }^{29}$ RUGGIE, John Gerard. Quando os negócios não são apenas negócios: as corporações multinacionais e os direitos humanos, 2014, p. 13.

${ }^{30}$ GONÇALVES, Alcindo; FONTOURA COSTA, José Augusto. Impasse nas negociações sobre mudanças climáticas. Revista Política Externa, v. 23, n. 03, 2015, p. 96.

${ }^{31}$ MATIAS, Eduardo Felipe P. A humanidade e suas fronteiras: do Estado soberano à sociedade global, p. 455.
} 
LIMA, Luciana Cristina da Conceição; REI, Fernando Cardozo Fernandes. O papel da Soft Law privada no enfrentamento da problemática socioambiental global. Revista Eletrônica Direito e Política, Programa de Pós-Graduação Stricto Sensu em Ciência Jurídica da UNIVALI, Itajaí, v.13, n.2, $2^{\circ}$ quadrimestre de 2018. Disponível em: www.univali.br/direitoepolitica - ISSN 1980-7791

processos de solução de problemas globais de diversos temas. As ONGs pressionam governos e empresas sobre assuntos, trazendo, muitas vezes, conhecimento, expertises e informações relevantes e necessárias para o andamento das negociações.

As ONGs têm sido o maior exemplo de representação de atores não estatais no cenário internacional, sendo "essenciais para a formação de uma consciência global e para o combate de determinados problemas comuns da humanidade"32. O estudo da participação desses atores no cenário internacional é de grande importância para o tema tratado neste ensaio, porque, se existem razões para o fenômeno da regulamentação global privada, uma delas está contida na participação de outros atores, localizados entre os Estados e as organizações com objetivos econômicos. As ONGs são atores que não pertencem aos Estados, mas que defendem interesses públicos ${ }^{33}$. Também não possuem finalidade econômica e, por isso, são capazes de gerar situações que forçam os outros atores a buscarem entendimento na adoção de práticas desejáveis sobre os diversos temas perseguidos, forçando, assim, que as empresas adotem práticas de proteção perante os impactos e danos ambientais e sociais gerados por suas atividades.

Esse novo cenário demanda estratégias e mecanismos de solução de conflitos e problemas que contem com a participação ampla de diversos atores globais e partes interessadas no seu enfrentamento. Demanda, principalmente, a interação e cooperação das partes interessadas para que novas ferramentas e estratégias sejam desenvolvidas e que possam integrar o processo global de governança. A necessidade de regulamentação da responsabilidade socioambiental das organizações privadas surge, então, da deficiência de regulamentação global, porque, "empresas que operam globalmente não são regulamentadas como tal"34.

\footnotetext{
32MATIAS, Eduardo Felipe P. A humanidade e suas fronteiras: do Estado soberano à sociedade global, p. 446.
}

${ }^{33}$ MATIAS, Eduardo Felipe P. A humanidade e suas fronteiras: do Estado soberano à sociedade global, p. 446.

\footnotetext{
${ }^{34}$ RUGGIE, John Gerard. Quando os negócios não são apenas negócios: as corporações multinacionais e os direitos humanos, p. 18.
} 
LIMA, Luciana Cristina da Conceição; REI, Fernando Cardozo Fernandes. O papel da Soft Law privada no enfrentamento da problemática socioambiental global. Revista Eletrônica Direito e Política, Programa de Pós-Graduação Stricto Sensu em Ciência Jurídica da UNIVALI, Itajaí, v.13, n.2, $2^{\circ}$ quadrimestre de 2018. Disponível em: www.univali.br/direitoepolitica - ISSN 1980-7791

E como consequência dessa lacuna, surgem as pressões e cobranças da sociedade civil por comportamentos mais éticos e transparentes.

Essas pressões fazem com que surjam movimentos em busca de mecanismos e ferramentas que ajudem na solução de conflitos e que permitam a construção de um processo de adequação às novas exigências. Nesse contexto, é que são desenvolvidas as normas socioambientais privadas. Diferentemente da lógica do Direito Internacional Público, essas normas não surgem por um acordo ou imposição dos Estados, sua iniciativa é privada. Contudo, seu processo de construção e elaboração abre espaço para a participação de diversos atores, mesmo não empresariais, incluindo ONGs e governos, interessados em cooperar pelo alcance de um objetivo comum ${ }^{35}$. O objetivo da "regulamentação civil" não é substituir os Estados. Contudo, acaba por ampliar o sistema de governança global existente, criando vínculos entre as regulamentações públicas e privadas. ${ }^{36}$ Esse vínculo pode ser estabelecido inclusive pela adoção das normas privadas ou algumas de suas diretrizes em normas legais, em acordos ou tratados multilaterais ${ }^{37}$.

Normas socioambientais privadas são iniciativas voluntárias, consideradas como soft $l a w^{38}$ por não serem obrigatórias e a princípio não vinculantes, mas que decorrem da necessidade que as empresas transnacionais e outras organizações possuem em desenvolver e adotar práticas e condutas consideradas adequadas

\footnotetext{
${ }^{35}$ LAMOTTE, K. Russell. Mechanisms for Global Agreements. In: International environmental law, Roger R. Martella Jr. e J. Brett Grosko (eds. )- First edition. J. Brett, editor, 2014, p. 966.

${ }^{36}$ VOGEL, David. The private regulation of global corporate conduct. Center for Responsible Business, 2006, p.06.

${ }^{37}$ ROHT-ARRIAZA, Naomi. Shifting the Point of Regulation: The International Organization for Standardization and Global Lawmaking on Trade and the Environment. 22 Ecology Law Q, 1995. Disponível em: < http://scholarship.law.berkeley.edu/elq/vol22/iss3/1>. Acesso em 12 mar. 2017.

${ }^{38}$ SHELTON, Dinah. Soft law. Routledge handbook of international law, Routledge Press; GWU Legal Studies Research Paper No. 322; GWU Law School Public Law Research Paper No. 322, 2009. Disponível em: <http://ssrn.com/abstract=1003387>. Acesso em 21 jan. 2017.
} 
LIMA, Luciana Cristina da Conceição; REI, Fernando Cardozo Fernandes. O papel da Soft Law privada no enfrentamento da problemática socioambiental global. Revista Eletrônica Direito e Política, Programa de Pós-Graduação Stricto Sensu em Ciência Jurídica da UNIVALI, Itajaí, v.13, n.2, $2^{\circ}$ quadrimestre de 2018. Disponível em: www.univali.br/direitoepolitica - ISSN 1980-7791

por seus stakeholders ${ }^{39}$. São práticas que, muitas vezes, coadunam com regras já estabelecidas em acordos multilaterais e em regimes internacionais, mas, que por razões diversas não possuem mecanismos que alcancem diretamente alguns setores.

Retoma-se, então, à questão da incapacidade dos Estados nacionais em criar mecanismos para obrigar as empresas a adotarem práticas mais éticas e sustentáveis, condizentes com a expectativa dos acordos globais. Esta lacuna encontrada na regulamentação jurídica das questões socioambientais, decorrente da dificuldade global dos Estados em controlar as ações e impactos das empresas transnacionais, somada às pressões de outros atores importantes no cenário global por práticas empresariais mais éticas, eficientes, justas e responsáveis, proporcionam a ascensão de uma "inovadora forma de governança"40, que se traduz pela criação de normas voluntárias, que permitem a crescente elaboração e utilização de mecanismos não estatais de solução de controvérsias em âmbito global.

Nesse contexto, é possível encontrar programas globais essencialmente privados que têm obtido êxito em questões socioambientais. Os Programas de certificação florestal são exemplos de mecanismos, "desenvolvidos em grande parte por ONGs ambientais e associações industriais, que estabelecem padrões globais para o manejo florestal adequado ${ }^{41}$. Esse exemplo é importante porque, além de demonstrar a organização de determinados grupos no estabelecimento de consensos normativos voluntários, traz também a possibilidade de se tratar temas

\footnotetext{
39 VOGEL, David. The private regulation of global corporate conduct. Center for Responsible Business, 2006, p. 5.

${ }^{40}$ VOGEL, David. The private regulation of global corporate conduct. Center for Responsible Business, 2006, p. 7.

${ }^{41}$ MEIDINGER, Errol. The administrative law of global private-public regulation: the case of forestry. European Journal of International Law, v. 17, n. 1, p. 47-87, 2006.
} 
LIMA, Luciana Cristina da Conceição; REI, Fernando Cardozo Fernandes. O papel da Soft Law privada no enfrentamento da problemática socioambiental global. Revista Eletrônica Direito e Política, Programa de Pós-Graduação Stricto Sensu em Ciência Jurídica da UNIVALI, Itajaí, v.13, n.2, $2^{\circ}$ quadrimestre de 2018. Disponível em: www.univali.br/direitoepolitica - ISSN 1980-7791

aparentemente considerados como locais, como a proteção florestal, através de um sistema de governança global ${ }^{42}$.

Esse sistema vem sendo construído por grupos de trabalho que contam com grande participação de ONGs ambientais, empresas, representantes da classe trabalhadora, que estabelecem alianças e um sistema de cooperação mútua. Nesse processo, também há a participação dos governos e Organizações Internacionais (OIs). Sendo assim, pode ser considerado como um sistema originalmente privado/público de "autoridade compartilhada"43.

Dessa forma, se por um lado existe a deficiência do Estado em regulamentar as ações das empresas que atuam globalmente, por outro, encontra-se um setor empresarial redirecionando fluxos de investimento voltados aos desafios e compromissos de responsabilidade socioambiental e uma sociedade civil cada vez mais organizada e capaz de pressionar as empresas, na construção de mecanismos próprios e que atendam as demandas globais. Este cenário é campo fértil para o surgimento de normas privadas, refletindo a expectativa das partes interessadas pela solução de problemas comuns em um sistema de governança global, com participação ampliada, que tem demonstrado aceitação e efetividade na sua aplicação.

\footnotetext{
${ }^{42}$ MEIDINGER, Errol. The administrative law of global private-public regulation: the case of forestry. European Journal of International Law, v. 17, n. 1, p. 47-87, 2006.

${ }^{43}$ MEIDINGER, Errol. The administrative law of global private-public regulation: the case of forestry. European Journal of International Law, v. 17, n. 1, p. 47-87, 2006.
} 
LIMA, Luciana Cristina da Conceição; REI, Fernando Cardozo Fernandes. O papel da Soft Law privada no enfrentamento da problemática socioambiental global. Revista Eletrônica Direito e Política, Programa de Pós-Graduação Stricto Sensu em Ciência Jurídica da UNIVALI, Itajaí, v.13, n.2, $2^{\circ}$ quadrimestre de 2018. Disponível em: www.univali.br/direitoepolitica - ISSN 1980-7791

\section{NORMAS SOCIOAMBIENTAIS PRIVADAS: MECANISMOS NÃO ESTATAIS DE SOLUÇÃO DE CONTROVÉRSIAS GLOBAIS}

Como já visto, as normas privadas são concebidas como instrumentos soft law, por serem voluntárias e flexíveis. Sua legitimidade advém dos atores envolvidos no seu processo construtivo, sendo aceitas e adotadas por diversas organizações do mundo, tornando-se referenciais internacionais de práticas e procedimentos para diversos tipos de atividades. A flexibilidade dessas normas permite que elas respondam de forma mais adequada às "necessidades de adaptação e evolução de determinadas questões, situação que supera "a necessidade de segurança jurídica" 44. Além disso, essa espécie normativa possibilita a participação de atores estatais e não-estatais no seu processo de construção, característica que possibilita troca de experiências e conhecimentos em um contexto de problemas, que necessitam mais de cooperação que de regras rígidas e coercitivas previamente definidas.

As questões socioambientais são os exemplos de situações em que esse tipo normativo se adequa. Os problemas relacionados à poluição e degradação do meio ambiente não se restringem mais ao território dos Estados, passando a ser assunto de interesse global ${ }^{45}$. Os problemas ambientais, por exemplo, tornaram-se transfronteiriços, projetando-se do plano nacional para 0 internacional ${ }^{46}$, fenômeno denominado como "internacionalização dos problemas ambientais" ${ }^{47}$.

44 BOISSON DE CHAZOURNES, Laurence. Normes, standards et règles en droit international. In: Brosset, Estelle. et al. Les enjeux de la normalisation technique internationale: entre environnement, santé et commerce international. Paris: La Documentation Française. p. 43$56,2006$.

45 RUIZ, José J. El derecho internacional frente al desafío del cambio climático. In: Cursos de derecho internacional y relaciones internacionales, de Vitoria-Gasteiz 2008. Universidad del País Vasco. p. 19-80, 2009.

${ }^{46}$ RUIZ, José J. El Derecho Internacional frente a los desafios ambientales globales. In: ALONSO, Esteban Juan Pérez (ed.). Derecho, globalización, riesgo y medio ambiente. Tirant lo Blanch. p. $119-141,2012$, p. 119.

${ }^{47}$ RUIZ, José J. El Derecho Internacional frente a los desafios ambientales globales. In: ALONSO, Esteban Juan Pérez (ed.). Derecho, globalización, riesgo y medio ambiente. Tirant lo Blanch. p. $119-141,2012$, p. 122. 
LIMA, Luciana Cristina da Conceição; REI, Fernando Cardozo Fernandes. O papel da Soft Law privada no enfrentamento da problemática socioambiental global. Revista Eletrônica Direito e Política, Programa de Pós-Graduação Stricto Sensu em Ciência Jurídica da UNIVALI, Itajaí, v.13, n.2, $2^{\circ}$ quadrimestre de 2018. Disponível em: www.univali.br/direitoepolitica - ISSN 1980-7791

Importantes exemplos de normas não vinculantes, produzidas neste contexto, são as normas técnicas socioambientais da $\mathrm{ISO}^{48}$. Tratam-se de instrumentos normativos voluntários que contam com um verdadeiro processo de governança na sua elaboração, permitindo a participação ampliada, diálogo e cooperação para o encontro de caminhos viáveis e práticos. São normas baseadas e estruturadas em consensos que visam "modelar, modular e orientar o comportamento dos Estados e outros atores no cenário internacional"49. Não vinculam, mas podem adquirir força vinculante por diversos fatores, inclusive, podem ser utilizadas como complemento de outras normas com caráter mais obrigatório. Essa força "vinculante" também pode decorrer da pressão exercida pela sociedade civil e outras partes interessadas para que as organizações adotem e cumpram seus requisitos. ${ }^{50}$

No campo socioambiental, a ISO possui importantes normas como a norma ISO 14001, que trata da gestão ambiental das organizações, contribuindo para que a organização institua uma política ambiental. Já a norma ISO 26000 de Responsabilidade Social ${ }^{51}$, apesar de não ser certificável, tem sido bastante aceita pela comunidade internacional, tendo como objetivo auxiliar as organizações na

\footnotetext{
${ }^{48}$ A ISO - International Organization for Standardization, sediada em Genebra na Suíça, é uma organização internacional, de caráter privado, que tem desempenhado um importante papel no desenvolvimento de iniciativas socioambientais. A organização ISO foi criada em 1946, logo após a Segunda Guerra Mundial, em uma reunião em Londres, contando com a participação de 25 países. O objetivo foi criar um organismo internacional que fosse capaz de elaborar padrões normativos globais de produtos e serviços. A ISO conta hoje com representatividade de 163 países, através de órgãos de normalização internos. No Brasil, a ISO é representada pela a ABNT - Associação Brasileira de Normas Técnicas. A ISO possui hoje um referencial de 21.582 normas internacionais publicadas, sendo considerada um dos mais importantes organismos normativos internacionais. ISO International Organization for Standardization - Sobre a ISO. Disponível em: $<$ http://www.iso.org/iso/home.html> Acesso em 12 jan. 2017.
}

${ }^{49}$ BOISSON DE CHAZOURNES, Laurence. Normes, standards et règles en droit international. In: Brosset, Estelle. et al. Les enjeux de la normalisation technique internationale: entre environnement, santé et commerce international. Paris: La Documentation Française. p. 43$56,2006$.

${ }^{50}$ ROHT-ARRIAZA, Naomi. Shifting the Point of Regulation: The International Organization for Standardization and Global Lawmaking on Trade and the Environment. 22 Ecology Law Q, 1995. Disponível em: < http://scholarship.law.berkeley.edu/elq/vol22/iss3/1>. Acesso em 12 mar. 2017.

${ }^{51}$ ABNT. Associação Brasileira de Normas Técnicas. NBR ISO 26000: Diretrizes sobre responsabilidade social, Rio de Janeiro, 2010. 
LIMA, Luciana Cristina da Conceição; REI, Fernando Cardozo Fernandes. O papel da Soft Law privada no enfrentamento da problemática socioambiental global. Revista Eletrônica Direito e Política, Programa de Pós-Graduação Stricto Sensu em Ciência Jurídica da UNIVALI, Itajaí, v.13, n.2, $2^{\circ}$ quadrimestre de 2018. Disponível em: www.univali.br/direitoepolitica - ISSN 1980-7791

adoção de práticas que contribuam para adequar e tornar o sistema de gestão de qualquer organização sustentável e em conformidade com as principais normas e procedimentos de proteção aos direitos humanos e meio ambiente. A ISO 26000 é um importante instrumento normativo internacional e voluntário sobre a responsabilidade social e desenvolvimento sustentável. Suas diretrizes são recomendadas e foram construídas em longo processo de governança que contou com a participação de atores estatais e não estatais.

A mais recente norma da ISO que revela claramente a importância da participação das organizações privadas nos processos públicos é a norma ISO 37001 - Sistemas de gestão antissuborno. Trata-se de norma privada que possui o objetivo de ajudar as organizações a "combater o suborno, por meio de uma cultura de integridade, transparência e conformidade com as leis e regulamentações aplicáveis"52.

A adoção de normas privadas voluntárias pode decorrer, ainda, da necessidade de inserção da organização em determinado mercado, situação que relativiza a característica não vinculante de algumas normas, principalmente de normas técnicas. Um exemplo disso é a questão internacional em torno da comercialização de madeira ilegal, que, apesar de alguns países criarem suas próprias leis e regimes bilaterais para regulamentar a questão, o sistema privado de certificação é o que tem demonstrado alcance mais amplo e efetivo para solucionar o problema ${ }^{53}$. Geralmente, as normas privadas, especialmente as normas técnicas, trazem em seu escopo a padronização de práticas, produtos, serviços, processos e produtos, com a finalidade de estabelecer um parâmetro único para os sistemas das organizações de forma a nivelar e uniformizar, com foco em resultados que, no fim, vão responder às necessidades de cada setor em solucionar os problemas e conflitos que desencadearam a sua elaboração e aplicação.

\footnotetext{
${ }^{52}$ ABNT. Associação Brasileira de Normas Técnicas. ISO 37001 - Sistemas de Gestão Antissuborno, 2016. Disponível em:< http://abnt.org.br/noticias/4949-iso-37001-sistemas-degestao-antissuborno>. Acesso em: 23 mar. 2017.

${ }^{53}$ BARTLEY, Tim. Transnational governance as the layering of rules: Intersections of public and private standards. Theoretical inquiries in law. v. 12, n. 02, p. 517-42, 2011.
} 
LIMA, Luciana Cristina da Conceição; REI, Fernando Cardozo Fernandes. O papel da Soft Law privada no enfrentamento da problemática socioambiental global. Revista Eletrônica Direito e Política, Programa de Pós-Graduação Stricto Sensu em Ciência Jurídica da UNIVALI, Itajaí, v.13, n.2, $2^{\circ}$ quadrimestre de 2018. Disponível em: www.univali.br/direitoepolitica - ISSN 1980-7791

Por outro lado, diversos são os questionamentos sobre os limites e alcances dessas normas. Uma das principais críticas é justamente sobre seu caráter não vinculante que, por consequência, não gera punições pelo seu descumprimento ${ }^{54}$, situação que pode colocar em xeque a credibilidade e, por consequência a eficácia da norma. Na mesma linha, os que observam que, além de fraco, porque não cogente, tal instituto tem o intuito de encorajar sua transformação em direito positivo ${ }^{55}$.

Roht-Arriaza (1995) questiona também a fragilidade do aspecto voluntário atribuído ao uso dessas normas, já que elas podem ser adotadas como complemento de normas jurídicas vinculantes e, portanto, tornam-se obrigatórias por força de lei ${ }^{56}$. Além disso, a autora explica que a "obrigatoriedade" no uso de normas não vinculantes, como as normas técnicas, por exemplo, pode decorrer de pressões das partes interessadas nas atividades das empresas como: ONGs, representantes das indústrias, sindicatos, trabalhadores e consumidores e outras organizações que negociam com essas empresas ${ }^{57}$. Situação essa que pode dificultar a atuação das empresas em determinados mercados, condicionando a atuação ao uso da norma ${ }^{58}$. Nesse caso, a norma pode ser benéfica por um lado, quando permite a padronização das atividades, buscando melhor aproveitamento do produto, preservação ambiental e respeito a direitos humanos, por exemplo.

54 GILBERT, Dirk Ulrich; RASCHE, Andreas; WADDOCK, Sandra. Accountability in a global economy: The emergence of international accountability standards. Business Ethics Quarterly. v. 21, n. 01, p. 23-44, 2011.

55 EISEMANN, Pierre Michel. The gentleman's agreement comme source du droit international. Jounal du Droit International. 1979, p. 326-348.

${ }^{56}$ ROHT-ARRIAZA, Naomi. Shifting the Point of Regulation: The International Organization for Standardization and Global Lawmaking on Trade and the Environment. 22 Ecology Law Q, 1995. Disponível em: < http://scholarship.law.berkeley.edu/elq/vol22/iss3/1>. Acesso em 12 mar. 2017.

57 ROHT-ARRIAZA, Naomi. Shifting the Point of Regulation: The International Organization for Standardization and Global Lawmaking on Trade and the Environment. 22 Ecology Law Q, 1995. Disponível em: < http://scholarship.law.berkeley.edu/elq/vol22/iss3/1>. Acesso em 12 mar. 2017.

58 WARD, Halina, HA, Mai-Lan. Voluntary Social and Environmental Standards and Public Governance: Reviewing the Evidence and Setting Principles for Standards-setters. The Foundation for Sustainable Development and Democracy and the Pacific Institute, September, 2012. Disponível em: <http://www2.pacinst.org/wp-content/uploads/2013/06/pacinst-standards-andpublic-governance-review-nov-2012.pdf>. Acesso em 25 abr. 2016. 
LIMA, Luciana Cristina da Conceição; REI, Fernando Cardozo Fernandes. O papel da Soft Law privada no enfrentamento da problemática socioambiental global. Revista Eletrônica Direito e Política, Programa de Pós-Graduação Stricto Sensu em Ciência Jurídica da UNIVALI, Itajaí, v.13, n.2, $2^{\circ}$ quadrimestre de 2018. Disponível em: www.univali.br/direitoepolitica - ISSN 1980-7791

Mas, por outro lado, pode se tornar uma barreira técnica para o acesso ao mercado.

Contudo, acredita-se que, apesar dessas limitações, as normas socioambientais privadas, por sua característica de norma mais pragmática e flexível, "refletem uma solução oportuna e realista para resolver os problemas sociais e ambientais" 59 . Dessa forma, entende-se que, no campo da regulamentação das atividades empresariais globais, a padronização, realizada através de instrumentos normativos, a princípio voluntários e não vinculantes, são concebidos como ferramentas adequadas para a inclusão das empresas e monitoramento de suas atividades no cenário internacional.

\section{CONSIDERAÇÕES FINAIS}

O atual cenário internacional possui aspectos irreversíveis de mudança no papel dos atores que compõem a comunidade global. A velocidade das informações, o avanço tecnológico, a disseminação de conhecimento e a possibilidade de troca de expertises e tecnologias têm demonstrado que a participação e responsabilização de outros atores é fundamental numa dinâmica de governança. A análise desse fenômeno identificou lacuna na regulamentação jurídica dos Estados, referente ao controle da responsabilidade socioambiental das organizações privadas.

A regulamentação privada das questões socioambientais é necessidade e realidade no cenário internacional, já que a inclusão e responsabilização das organizações privadas são estratégicas e necessárias para o enfrentamento dos complexos problemas contemporâneos. Para atender essa demanda, constata-se grande ascensão de normas, não vinculantes e de uso voluntário, que buscam exprimir consensos estabelecidos entre diversos atores reunidos para enfrentar problemas comuns.

As normas socioambientais privadas surgem, então, como ferramentas capazes de contribuir para o processo de governança global estabelecido. São instrumentos

\footnotetext{
59 GILBERT, Dirk Ulrich; RASCHE, Andreas; WADDOCK, Sandra. Accountability in a global economy: The emergence of international accountability standards. Business Ethics Quarterly. v. 21, n. 01, p. 23-44, 2011.
} 
LIMA, Luciana Cristina da Conceição; REI, Fernando Cardozo Fernandes. O papel da Soft Law privada no enfrentamento da problemática socioambiental global. Revista Eletrônica Direito e Política, Programa de Pós-Graduação Stricto Sensu em Ciência Jurídica da UNIVALI, Itajaí, v.13, n.2, $2^{\circ}$ quadrimestre de 2018. Disponível em: www.univali.br/direitoepolitica - ISSN 1980-7791

traduzidos em padrões, diretrizes e requisitos alinhados com importantes normas internacionais já estabelecidas para que as organizações de qualquer tipo e tamanho consigam gerir seus negócios com responsabilidade socioambiental, em paralelo à conformidade legal.

Contudo, há limites referentes ao real alcance dessas normas, em decorrência da sua não obrigatoriedade e, por outro lado, da possibilidade de utilização como barreira técnica. No entanto, verifica-se que a soft law privada, vista como um instrumento resultante de diálogo e cooperação no cenário internacional, sobretudo é capaz de contribuir para minimizar a lacuna de regulamentação jurídica identificada, justamente por trazer as empresas e outros atores para esse campo de tomada de decisões e estabelecimento de consensos e, ainda, por definir estratégias de ação desses atores, através do reconhecimento e de distribuição de responsabilidades.

Em suma, as normas socioambientais privadas definem uma estrutura comum de procedimentos que ajuda as empresas a cumprir compromissos voluntários, alinhados com agendas globais, de forma mais consistente e efetiva com as partes interessadas a respeito do seu impacto e desempenho atual e futuro.

\section{REFERÊNCIAS DAS FONTES CITADAS}

ABBOTT, Kenneth W.; SNIDAL, Duncan. Hard and soft law in international governance. International organization, v. 54, n. 03, p. 421-456, 2000.

ABNT. Associação Brasileira De Normas Técnicas. NBR ISO 26000: Diretrizes sobre responsabilidade social. Rio de Janeiro: ABNT, 2010.

ABNT. Associação Brasileira de Normas Técnicas. ISO 37001 - Sistemas de Gestão Antissuborno, 2016. Disponível em: < http://abnt.org.br/noticias/4949iso-37001-sistemas-de-gestao-antissuborno>. Acesso em: 23 mar. 2017.

BARTLEY, Tim. Transnational governance as the layering of rules: Intersections of public and private standards. Theoretical inquiries in law. v. 12, n. 02, p. 51742, 2011.

BEYERLIN, UIrich; MARAUHN, Thilo. International Environmental Law. Oxford: Hart Publishing, 2011.

BOISSON DE CHAZOURNES, Laurence. Normes, standards et règles en droit international. In: Brosset, Estelle. et al. Les enjeux de la normalisation 
LIMA, Luciana Cristina da Conceição; REI, Fernando Cardozo Fernandes. O papel da Soft Law privada no enfrentamento da problemática socioambiental global. Revista Eletrônica Direito e Política, Programa de Pós-Graduação Stricto Sensu em Ciência Jurídica da UNIVALI, Itajaí, v.13, n.2, $2^{\circ}$ quadrimestre de 2018. Disponível em: www.univali.br/direitoepolitica - ISSN 1980-7791

technique internationale: entre environnement, santé et commerce international. Paris: La Documentation Française. p. 43-56, 2006.

DODDS, Felix. The context: Multi-stakeholder processes and global governance. In: Hemmati M. (ed.), Multi-Stakeholder Processes for Governance and Sustainability: Beyond Deadlock and Conflict. London: Earthscan Publications. p. 26-34, 2002.

EISEMANN, Pierre Michel. The gentleman's agreement comme source du droit international. Jounal du Droit International. 1979, p. 326-348.

FREEMAN, R. Edward. The stakeholder approach revisited. Zeitschrift für Wirtschafts-und Unternehmensethik, v. 5, n. 3, p. 228, 2004. Disponível em: < http://citeseerx.ist.psu.edu/viewdoc/download?doi=10.1.1.466.6445\&rep=rep1\& type $=$ pdf $>$. Acesso em 10 fev. 2017.

FRIEDRICH, Jürgen. International Environmental soft law: The Functions and Limits of Nonbinding Instruments in International Environmental Governance and Law. Heidelberg; New York: Springer, 2013.

GIDDENS, Anthony. As consequências da modernidade. Unesp, 1990.

GILBERT, Dirk Ulrich; RASCHE, Andreas; WADDOCK, Sandra. Accountability in a global economy: The emergence of international accountability standards. Business Ethics Quarterly, v. 21, n. 01, p. 23-44, 2011.

GONÇALVES, Alcindo. Governança Global. In: GONÇALVES, Alcindo e COSTA, José Augusto Fontoura. Governança Global e Regimes Internacionais. São Paulo: Almedina, 2011.

GONÇALVES, Alcindo; FONTOURA COSTA, José Augusto. Impasse nas negociações sobre mudanças climáticas. Revista Política Externa, v. 23, n. 03, 2015.

IANNI, Octavio. Globalização: novo paradigma das ciências sociais. Estud. av., São Paulo, v. 8, n. 21, p. 147-163, ago. 1994. Disponível em: <http://www.scielo.br/scielo.php?script=sci_arttext\&pid=S0103-

40141994000200009\&Ing=en\&nrm=iso >. Acesso em: $12 \mathrm{fev}$. 2017. http://dx.doi.org/10.1590/S0103-40141994000200009.

ISO. International Organization for Standardization. ISO and social responsibility, $2008 . \quad$ Disponível em: <http://www.iso.org/iso/socialresponsibility.pdf>. Acesso em: 12 jan. 2017.

ISO. International Organization for Standardization. Standards. Disponível em: < http://www.iso.org/iso/iso14000>. Acesso em: 12 jan. 2017.

ISO. International Organization for Standardization. The ISO Survey. 2014. Disponível

em:<http://www.iso.org/iso/iso_catalogue/management_standards/certification/ the_iso_survey.htm>. Accesso em: 17 jan. 2017. 
LIMA, Luciana Cristina da Conceição; REI, Fernando Cardozo Fernandes. O papel da Soft Law privada no enfrentamento da problemática socioambiental global. Revista Eletrônica Direito e Política, Programa de Pós-Graduação Stricto Sensu em Ciência Jurídica da UNIVALI, Itajaí, v.13, n.2, $2^{\circ}$ quadrimestre de 2018. Disponível em: www.univali.br/direitoepolitica - ISSN 1980-7791

LAMOTTE, K. Russell. Mechanisms for Global Agreements. In: International environmental law, Roger R. Martella Jr. e J. Brett Grosko (eds. ) - First edition. J. Brett, editor, 2014.

MATIAS, Eduardo Felipe P. A humanidade e suas fronteiras: do Estado soberano à sociedade global. 4a ed. São Paulo: Paz e Terra, 2014.

MEIDINGER, Errol. The administrative law of global private-public regulation: the case of forestry. European Journal of International Law, v. 17, n. 1, p. 47-87, 2006.

NASSER, Salem Hikmat. Desenvolvimento, costume internacional e soft law. Direito Internacional e Desenvolvimento, v. 1, p. 201-218, 2005.

ROHT-ARRIAZA, Naomi. Shifting the Point of Regulation: The International Organization for Standardization and Global Lawmaking on Trade and the Environment. 22 Ecology Law Q, 1995. Disponível em: < http://scholarship.law.berkeley.edu/elq/vol22/iss3/1>. Acesso em 12 mar. 2017.

RUGGIE, John Gerard. Quando os negócios não são apenas negócios: as corporações multinacionais e os direitos humanos. Trad. Isabel Murray $-1^{\text {a }}$ ed. - São Paulo: Editora Abril, 2014.

RUIZ, José J. El derecho internacional frente al desafío del cambio climático. In: Cursos de derecho internacional y relaciones internacionales, de VitoriaGasteiz 2008. Universidad del País Vasco. p. 19-80, 2009.

RUIZ, José J. El Derecho Internacional frente a los desafios ambientales globales. In: ALONSO, Esteban Juan Pérez (ed.). Derecho, globalización, riesgo y medio ambiente. Tirant lo Blanch. p. 119-141, 2012.

SALMON, Jean. Dictionnaire de droit international public. Bruxelas : Bruylant, 2001. p. 1039.

SHELTON, Dinah L. Soft law. Handbook of international law, Routledge Press; GWU Legal Studies Research Paper No. 322; GWU Law School Public Law Research Paper No. 322, 2009. Disponível em: <http://ssrn.com/abstract $=1003387>$. Acesso em 21 jan. 2017.

VIRALLY, Michel. La valeur juridique des recommandations des organisations internationales. Annuaire français de droit international, v. 2, n. 1, p. 66-96, 1956.

VOGEL, David. The private regulation of global corporate conduct. Center for Responsible Business, 2006.

WARD, Halina, HA, Mai-Lan. Voluntary Social and Environmental Standards and Public Governance: Reviewing the Evidence and Setting Principles for Standards-setters. The Foundation for Sustainable Development and Democracy and the Pacific Institute, September, 2012. Disponível em: 
LIMA, Luciana Cristina da Conceição; REI, Fernando Cardozo Fernandes. O papel da Soft Law privada no enfrentamento da problemática socioambiental global. Revista Eletrônica Direito e Política, Programa de Pós-Graduação Stricto Sensu em Ciência Jurídica da UNIVALI, Itajaí, v.13, n.2, $2^{\circ}$ quadrimestre de 2018. Disponível em: www.univali.br/direitoepolitica - ISSN 1980-7791

<http://www2.pacinst.org/wp-content/uploads/2013/06/pacinst-standards-andpublic-governance-review-nov-2012.pdf>. Acesso em 25 abr. 2016.

ZERK, Jennifer A. Multinationals and corporate social responsibility: Limitations and opportunities in international law. Cambridge University Press, 2006.

Recebido em: 25/06/2017

Aprovado em: 06/08/2018 